\title{
Effects of anti-IgE in asthmatic subjects
}

\author{
Anthony J Frew
}

University Medicine, Southampton General Hospital, Southampton SO16 6YD, UK

Introductory articles

The effect of an anti-IgE monoclonal antibody on the early- and late-phase responses to allergen inhalation in asthmatic subjects

JV Fahy, HE Fleming, HH Wong, JT Liu, JQ Su, J Reimann, RB Fick, HA Boushey

A humanized murine monoclonal antibody directed to the Fc\&R1-binding domain of human $\lg E$ (rhuMAb-E25) has been shown to inhibit the binding of IgE to mast cells without provoking mast cell activation. To examine the effects of neutralizing IgE on allergic airway responses, we assessed the effects of 9 wk of treatment with rhuMAb-E25 in a parallel group, randomized, double-blind, placebocontrolled study of 19 allergic asthmatic subjects. We found that treatment with rhuMAb-E25 reduced the serum IgE, increased the dose of allergen needed to provoke an early asthmatic response, reduced the mean maximal fall in FEV 1 during the early response $(30 \pm 10 \%$ at baseline to $18.8 \pm 8 \%$, versus $33 \pm 8 \%$ at baseline to $34 \pm 4 \%$ after placebo; $p=0.01$ ), and reduced the mean maximal fall in FEV during the late response $(24+20 \%$ at baseline to $9+10 \%$ versus $20+17 \%$ at baseline to $18+17 \%$ after placebo; $p=0.047)$. We conclude that an anti-IgE monoclonal antibody, which inhibits binding of IgE to its receptor, suppresses the early- and late-phase responses to inhaled allergen in allergic asthmatic subjects. Targeting IgE with rhuMAb-E25 might be a useful treatment for allergic asthma. (Am J Respir Crit Care Med 1997;155:1828-1834)

Inhibitory effects of an anti-lgE antibody E25 on allergen-induced early asthmatic response

L-P Boulet, KR Chapman, J Côté, S Kalra, R Bhagat, VA Swystun, M Laviolette, LD Cleland,

F Deschesnes, JQ Su, A Devault, RB Fick, DW Cockcroft

Inhaled allergens, acting through IgE-dependent mechanisms, are important triggers of asthma symptoms and inducers of airway hyperresponsiveness and airway inflammation. The effect of anti-lgE recombinant humanized monoclonal antibody-E25 (rhuMAb-E25) on the provocation concentration of allergen causing a $15 \%$ fall in $F E V_{1}$ (allergen $P C_{15}$ ) during the allergen-induced early asthmatic response (EAR) was assessed in a multicenter, randomized, double-blind, parallel group study. Ten of 11 allergic asthmatic subjects randomized to receive intravenous rhuMAb-E25, $2 \mathrm{mg} / \mathrm{kg}$ on study day 0 and $1 \mathrm{mg} /$ $\mathrm{kg}$ on Days 7, 14, 28, 42, 56, and 70 completed the study; nine received intravenous placebo. The allergen $P C_{15}$ was measured on Days $-1,27,55$, and 77 and methacholine $P C_{20}$ on Days -2, 42, and 76. rhuMAb-25 was well tolerated and only one patient (active group) was withdrawn because of a generalized urticarial rash after the first dose. Compared with baseline values (Day -1), the median allergen $P C_{15}$ on Days 27, 55, and 77 were increased by 2.3, 2.2, and 2.7 doubling doses $\left(\Delta \log P C_{15} / 0.3\right)$ respectively with rhuMAb-E25 and $-0.3,+0.1$, and -0.8 doubling doses with placebo $(p \leq 0.002)$. Methacholine $P C_{20}$ improved slightly after rhuMAb-E25, this change becoming statistically significant on Day 76 ( $p<0.05)$; no change was observed in the placebo group. Mean serum-free lgE fell by $89 \%$ after rhuMAb-E25 while there was no significant change after placebo. The inhibitory effects of rhuMAb-E25 on allergen-induced EAR suggest that it may be an effective, novel antiallergic treatment for asthma. (Am J Respir Crit Care Med 1997;155:1835-1840) 
The role of IgE in induction, maintenance and triggering of asthma

The link between allergy and asthma is long established and the majority of patients with asthma have evidence of $\operatorname{IgE}$ mediated hypersensitivity to airborne allergens. ${ }^{1}$ This is especially true of children with asthma, among whom over $85 \%$ will show positive skin tests to one or more airborne allergens. ${ }^{23}$ On the other hand, a significant proportion of adult asthmatic subjects have negative skin tests and no obvious external trigger factors other than viral infections. ${ }^{4}$ This group of "intrinsic" asthmatics often have quite severe disease and may respond less well to conventional drug therapy than those with obvious allergies. While IgE mediated allergy is clearly an important risk factor for the development of childhood asthma, it is less clear how important allergic triggers are in exacerbations of the disease or in the maintenance of ongoing asthma. In children exacerbations of asthma have been shown to correspond with episodes of viral upper respiratory tract infection, with over $85 \%$ of exacerbations linked temporally to (5) ${ }^{5}$ This relationship is also seen in adults although the proportion of asthma exacerbations in which rhinoviruses can be identified is rather lower at around 50\%. ${ }^{6}$ Anecdotally, exposure to cats or horses can trigger severe acute episodes of asthma, but the role of pollens in triggering acute episodes seems less certain. Admissions to hospital are in fact lower during the hay fever season than in the three months preceding or following the UK grass pollen season, but it seems likely that fragmented pollen grains may be responsible for the epidemics of acute asthma biated with thunderstorms. ${ }^{7}$

Allergen avoidance has been advocated in asthma and can lead to modest reductions in non-specific bronchial responsiveness ${ }^{8}$ but only extreme forms of avoidance have had any significant clinical benefit. ${ }^{9}$ In the context of occupational asthma where complete allergen avoidance is definitely achievable, it is clear that some patients improve mart tinue to have asthmatic symptoms for many years, even though they are no longer exposed to the allergen that induced their asthma. ${ }^{10}$ Factors that have been associated with the persistence of occupational asthma include the duration of exposure before developing symptoms, the duration of continuing exposure after the onset of asthma, and the persistence of airways eosinophilia " reducing the inflammatory process in allergic asthma, it seems likely that other factors also contribute to the maintenance of established allergic inflammation.

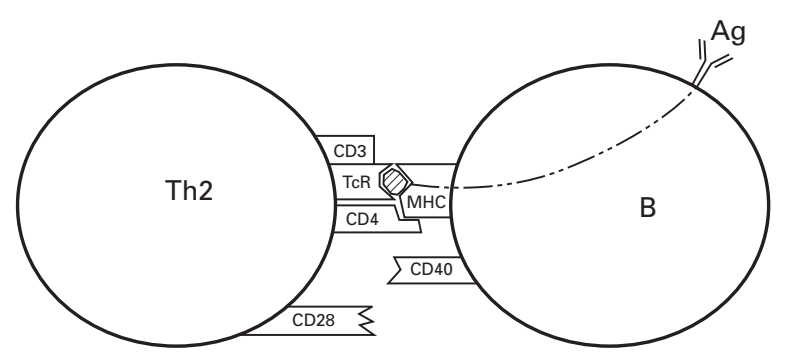

C

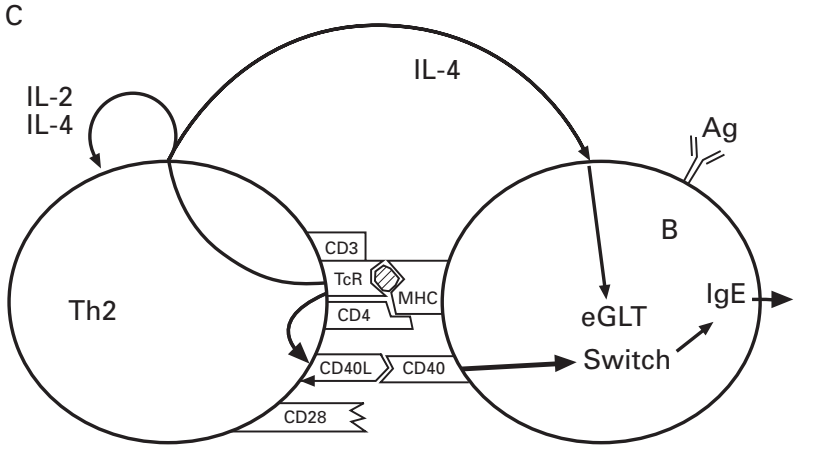

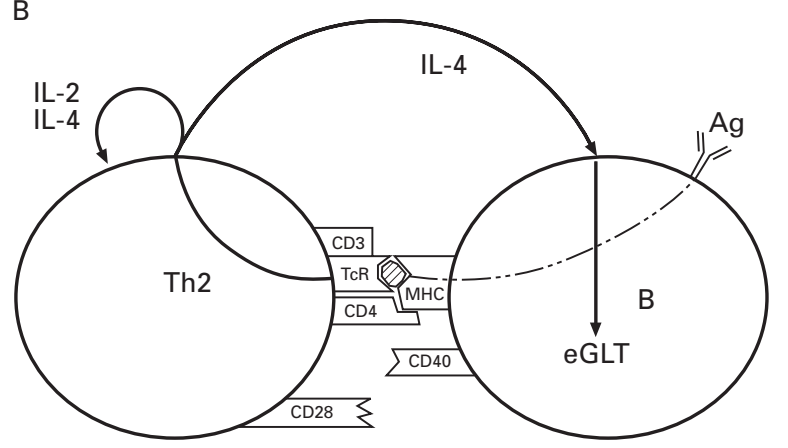

D

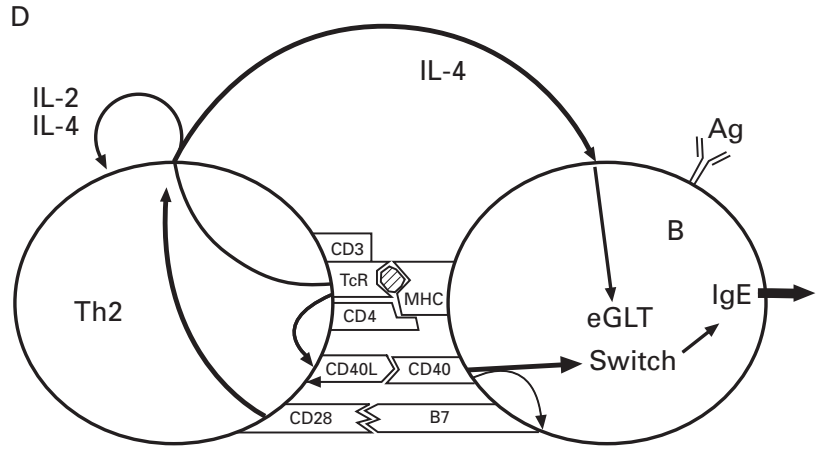

Figure 1 Two signal model of B cell isotype switching. On first exposure to any antigen, $B$ cells can make lgM without rapid response in the event of re-exposure. Memory $T$ cells recognising fragments of the antigen may also develop. To make $\mathrm{IgE}$, these two cell types must cooperate: in this model, a memory $B$ cell recognises the allergen via its surface immunoglobulin, thereby trapping it. The antigen is ingested and then digested into short fragments, which are then presented on the $B$ cell surface in the groove of MHC class II molecules. These antigen-MHC complexes are shown to passing $T$ cells within the regional lymph node or spleen. When a CD4 $4^{+} T$ cell that recognises the MHC-antigen fragment complex meets the antigen-presenting $B$ cell, the $T$ cell antigen receptor is activated, sending internal signals to the cell to produce
autocrine growth factors (for example, IL-2) as well as activating adhesion mechanisms to lock the two cells together. If the $T$ cell is preprogrammed to facilitate IgE switching (that is, a Th2 cell), then IL-4 is also produced; this has autocrine effects as well as inducing transcription of the Ce immunoglobulin gene in the B cell (germline transcripts). Upon activation the $T$ cell expresses CD40 ligand, which binds to CD40 on the $B$ cell surface and provides the second signal needed to switch the $B$ cell over to IgE production. Meanwhile, the $B$ cell displays the $B 7$ counter-receptor which signals via CD28 on the $T$ cell to augment IL-4 production. Under these twin influences the B cellipts. 
Much attention has been focused on the role of the cytokines IL- 4 and IL-5 in coordinating the inflammatory response in asthma. IL-4 provides a key signal in the process by which B cells switch over from making $\operatorname{IgM}$ or IgG antibodies towards making $\operatorname{IgE}$. This process of "isotype switching" is tightly controlled. On initial exposure to antigens the naive B cell can make IgA or IgM antibodies without requiring help from T cells. Concurrently, there is expansion of "memory" B
cells recognising parts of the antigen. Upon subsequent exposure memory $\mathrm{B}$ cells can process antigen and can use their surface MHC class II molecules to presen antigenic fragments to $\mathrm{T}$ cells, thereby obtaining help from $\mathrm{T}$ cells for making a secondary immune response (fig 1). In individuals predisposed to making IgE re(fig 1 ). In individuals predisposed to making IgE reIL- 4 and IL-5 (the so-called Th2 phenotype) and if IL-4 and IL-5 (the so-called Th2 phenotype) and if
such a T cell interacts with a memory B cell, then the such a $\mathrm{T}$ cell interacts with a memory $\mathrm{B}$ cell, then the $\mathrm{B}$ cell may be directed to switch over to make IgE. Two separate signals are required: a contact signal delivered through the CD40 molecule and its ligand, and a soluble signal delivered by IL-4 ${ }^{12}$ In man, but not in rodents, the cytokine IL-13 can substitute for IL- $4 .{ }^{13}$ IL- 4 was originally thought to be produced exclusively by $\mathrm{T}$ cells but, when bronchial and nasal biopsy specimens were stained for IL-4 protein, it was found that IL-4 protein was present mainly in mast cells. ${ }^{14}$ Mast cells release IL-4 when stimulated ${ }^{14}$ : in atopic subjects this may lead to an IL-4-rich environment in the bronchial mucosa and hence to immune deviation towards the Th2 phenotype and a greater likelihood of switching to IgE on subsequent exposure to potential allergens.

The cytokine IL-5 is intimately involved in the differentiation, maturation and activation of eosinophils. The eosinophil is derived from a common granulocyte bone marrow precursor cell and differentiates sequentially under the influence of IL-3, GM-CSF and finally IL-5 to become a mature eosinophil. ${ }^{15} \mathrm{IL}-5$ is also a selective activator of the mature eosinophil. ${ }^{16} \mathrm{IL}-5$ is made by T activator of the mature eosinophil. $\mathrm{IL}-5$ is made by $\mathrm{T}$

cells but has also been four
and epithelial cells. ${ }^{17-19}$

Although the genes for IL- 4 and IL- 5 are located very close together on chromosome $5 \mathrm{q} 31-33$, recent evidence indicates that their expression is not coordinately regulated. ${ }^{20}$ Expression of mRNA for IL-5 is a feature of both allergic and non-allergic asthma ${ }^{21}$ and there is a close correlation between $\mathrm{T}$ cell activation and serum IL-5 correlation between $\mathrm{T}$ cell activation and
concentrations in various forms of asthma. ${ }^{22}$

A number of interesting insights into the relative contributions of IL- 4 and IL- 5 to asthma have emerged in studies of occupational asthma to isocyanates. Isocyanate asthma is a particularly interesting model which bridges the gap between atopic asthma, where exposure to the inciting allergen is lifelong, and intrinsic asthma where, as far as we can tell, extrinsic allergens and IgE where, as far as we can tell, extrinsic allergens and IgE are not involved. Typically, isocyanate asthma develops
after a latent period in which exposure occurs without after a latent period in which exposure occurs without symptoms. IgE antibodies cannot be directly implicated but the histology of the bronchial mucosa is more or In biopsy specimens taken from patients with chronic isocyanate asthma there was upregulation of mRNA for IL-5 but not for IL-4, while when such patients for IL-5 but not for IL-4, while when such patients
underwent bronchial challenge there was upregulation underwent bronchial challenge there was upregulation
of both cytokines. ${ }^{25}$ To add further confusion, $\mathrm{T}$ cell of both cytokines. ${ }^{25}$ To add further confusion, $\mathrm{T}$ cell
clones derived from patients challenged with toluene diisocyanate were found to be predominantly CD8+ and secreted IL- 5 but little or no IL- $4 .^{26}$

Taken together, this cytokine evidence indicates that the expression of asthma is closely linked to upregulation of IL-5, while upregulation of IL-4 is perhaps more closely related to IgE and allergic sensitisation but not directly to the clinical syndrome of asthma. ${ }^{2}$

Experimental studies of the role of IL- 4 and IL- 5 in allergic disease have been hampered by the lack of a of are many models of allergic sensitisation and it is relatively easy to demonstrate that sensitised animals will develop airways eosinophilia and increased airways resistance, but these are essentially models of acute allergen exposure rather than models of the disease we recognise as asthma. In particular, almost none of the models give any long lasting airways inflammation or anything similar anything similar to the airways remodelling and deposition that occur in chronic human asthma. With these caveats, animal models have shown that $\mathrm{T}$ cells are the main source of IL- 5 , but not IL- 4 , in the lungs of antigen-challenged mice. ${ }^{28}$ Detailed discussion of these studies can be found elsewhere ${ }^{29}$ but it has been consistently shown that monoclonal antibodies directed against IL- 5 can prevent airways hyperresponsiveness in several species including mice, guinea pigs, and monin sever. ${ }^{30-32}$

\section{Immunotherapy for asthma}

Rather than attacking the messengers, could one not try to intervene at the level of the IgE antibody? This was for many years considered to be the basis for classical injection immunotherapy. The immunisation schedules for specific injection immunotherapy (SIT) were developed in the last years of the 19th and the first decade of the 20th centuries, long before the discovery of IgE in 1967. During the 1920s and 1930s the concept of "blocking antibodies" was popularised by Coca and Cooke and, indeed, it is true that SIT induces an increase in IgG antibodies directed against the injected allergen with a gradual decline in specific IgE titres after an initial increase. However, the beneficial effects of SIT come on much more rapidly than the antibody changes come on much more rapidly than the antibody changes
and it is now generally believed that SIT must work by a form of immune deviation, driving $\mathrm{T}$ cells away from the Th2 phenotype towards a Th1 phenotype. ${ }^{3}$

Although SIT is the treatment of choice for hymenoptera sensitivity and it retains a place in the management of allergic rhinitis, there is considerable about its value in the management of asthma. Firstly, there is less clarity about the importance of specific allergy in the expression of asthma; secondly, many patients are multiply sensitised and SIT is a highly targeted therapy which only addresses the allergen used in the injections; thirdly, and most importantly, there is no doubt that patients with asthma are at much greater risk of severe adverse reactions to SIT. Of the 27 UK fatalities associated with SIT between 1952 and 1985 , the precise indication for SIT was known in 17 cases, and 16 of these were being treated for asthma. ${ }^{34}$ This should be seen in the context that SIT was being given much more often for hay fever than for asthma. Similarly, in the confidential inquiry by the American Academy of Allergy and Immunology into deaths associated with asthma and the mor asthma and the mode of death was catastrophic bron-
chospasm rather than circulatory collapse or other feachospasm rather than
tures of anaphylaxis.

\section{Why try anti-IgE?}

It was against this background that steps were taken to try to develop more general forms of immunological 
therapy directed against IgE. Ordinary anti-IgE antibodies crosslink IgE bound to basophils or mast cells, and this then triggers degranulation and anaphylactictype reactions. Indeed, this effect of anti-IgE is the basis of several standard assays of mast cell function. Thus, any therapy directed against IgE has to avoid crosslinking IgE antibodies bound to mast cells. The approach taken was to develop antibodies directed against that portion of the IgE molecule which binds to the high affinity Fce receptor. Such an antibody should be able to bind free IgE molecules and then either remove the IgE from the circulation as immune complexes or else prevent the IgE from binding to the $\mathrm{F}_{\mathrm{C} \varepsilon}$ recepto due to steric hindrance. Of course, such an antibody would not be able to remove IgE antibodies that were already bound to mast cells through the Fce receptor so the value of such an approach in abolishing $\operatorname{IgE}$ mediated reactions will depend on whether cell bound $\operatorname{IgE}$ turns over rapidly or remains bound to the mast cells for a long time ${ }^{36}$

The development process followed by Genentech for E25 and the parallel work by CIBA ${ }^{37}$ took this concept and proceeded to generate monoclonal antibodies which recognise the Fc\&RI binding site of IgE. Suitable mouse antibodies which bound free IgE but did not stain mast cells were developed and then "humanised" by retaining the antigen combining site and engineering this into a human immunoglobulin $\left(\operatorname{IgG}_{1}\right)$ molecule. ${ }^{38}$ Once achieved, the antibody could be mass produced to yield sufficient quantities for use in man. The monoclonal sufficient quantities for use in man. The monoclonal well to free IgE but does not degranulate mast cells, so there is no specific risk of triggering anaphylaxis by causing widespread release of mast cell mediators. The antibody has been tested in atopic and non-atopic volunteers and is non-immunising in the sense that it does not induce antibodies directed against human IgG or directed against the anti-IgE combining site Prior experience with monoclonal antibody therapies suggests that "anti-idiotypic" antibodies may well develop with prolonged use as the human immune system should be tolerant of the constant part of IgG but does not have any system for specific tolerance to the idiotype (the specific antigenic features of the antibody combining site). Indeed, crossrecognition of idiotypes has long been considered an advantageous feature of the immune system, allowing downregulation of clones that become overexpressed and encouraging diversity within the antibody repertoire. ${ }^{41}$

One feature of E25 that may not be instantly obvious is that, although it will not bind to surface IgE that is bound to FceRI, it does have the potential for modulating or eliminating other cells bearing IgE which express the lower affinity IgE receptor (FceRII or CD23). CD23 is expressed by B cells, platelets, eos$\mathrm{CD} 23)$. CD23 is expressed by $\mathrm{B}$ cells, platelets, eos-
inophils, and some $\mathrm{T}$ cells and binds to IgE through a inophils, and some $\mathrm{T}$ cells and binds to IgE through a
completely separate site on the $\mathrm{Fc}$ portion of $\operatorname{IgE}^{42}$ so the E25 binding site should, at least theoretically, still be accessible and allow E25 to bind and eliminate those effector cells which bear FCERII.

What do the index papers really tell us and is E25 a viable therapy for asthma?

The two recent papers show firstly that E25 dramatically reduces the baseline concentration of circulating IgE. This is to be expected in the short term since the monoclonal antibody is specifically designed to bind free IgE molecules. Substantial concentrations of E25 could be measured up to 28 days after administration ${ }^{40}$ which may account for the persistent suppression of total and specific IgE. However, the production of $\operatorname{IgE}$ may be damped down as well. Another study using E25 has recently been published in which E25 was given to 240 patients with 240 patients with allergic rhinitis. Unlike the two index articles, ${ }^{39}$ Casale et al used three different treatment regimes (two different doses intravenously, one subcutaneously) plus corresponding placebo controls. The reduction in total and specific IgE concentrations was dose dependent but IgE was suppressed completely in only 11 of the 180 subjects who received active therapy. Both total and specific IgE remained low four weeks after the last infut but IgE concentrations had returned to by eight weeks after the last infusion.

The airways response to allergen challenge is known to depend on two principal parameters: the concentration of allergen-specific IgE and the degree of nonspecific bronchial reactivity. Indeed, this relationship is so tight that one can use skin test reactivity (a surrogate of allergen-specific IgE) and methacholine sensitivity to predict, with a reasonable dhe dose of allergen required to induce a $20 \%$ fall in $\mathrm{FEV}_{1}$. Given that E25 reduces total and specific IgE by 88 $89 \%$, it was to be expected that there would be a reduction in allergen induced bronchospasm provided that $\operatorname{IgE}$ was not permanently bound to airways mast cells. It is noteworthy that E25 did not affect the immediate skin test reaction, indicating that IgE bound to entent 5 on nonspecific bronchial responsiveness, as this gives us some indication of the degree to which background allergen exposure may be increasing the irritability of the bronchi. A twofold improvement in sensitivity was observed, which is modest, although it is clear from the paper that there was considerable interindividual variation in the extent of improvement, implying that some subjects improved a lot while others did not change at all. ${ }^{40}$

In the rhinitis study mentioned above, symptom scores were proportional to the residual concentrations of ragweed specific IgE, but there were no overall statistically significant differences in symptom scores between the five treatment groups. ${ }^{43}$ This study tells us that there may be a clinical effect on allergic rhinitis provided one can eliminate circulating allergen specific proved it cannot be assumed that ashma will necessarily respond in the same way since, even though asthma and rhinitis share some common basic mechanisms, the mechanisms of disease expressions are quite

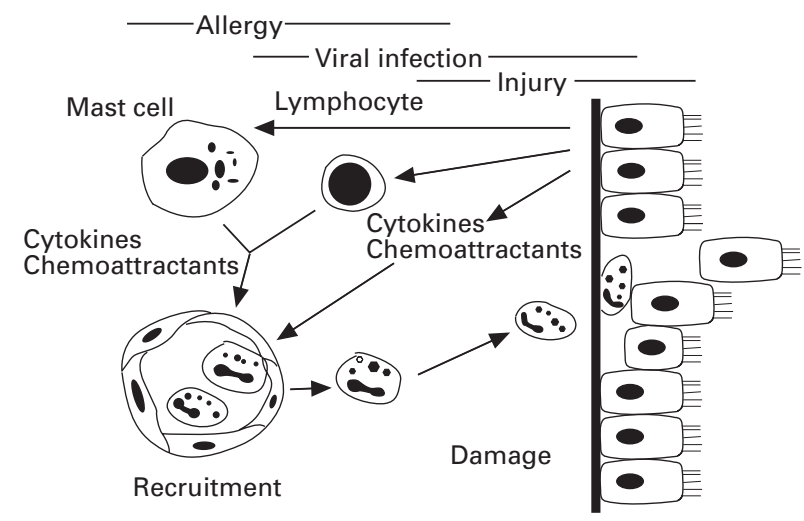

Figure 2 Allergy, viral infection and irritant stimuli as initiators of the asthmatic inflammatory response with subsequent self-perpetuating inflammation coordinated by
structural cells of the airway. 


\section{LEARNING POINTS}

* The role of IgE in asthma remains uncertain; it is obviously more important in children with atopic disease than in adults, only some of whom have clear evidence of allergic sensitisation.

* Anti-IgE antibodies that bind to free IgE but not to mast cell bound IgE can be administered safely to atopic patients without triggering anaphylaxis.

* Pretreatment with anti-lgE can blunt the response of sensitive individuals to inhaled allergen.

* A priori, there are several reasons for thinking that anti-IgE would be more effective in acute allergen challenge than in chronic asthma.

* Further trials are indicated in selected subgroups to address the efficacy of anti-lgE in real asthma.

* The clinical efficacy of anti-IgE may help to establish whether we should concentrate more on the trigger factors or the downstream consequences of asthma.

distinct. Rhinitis is mainly expressed through vascular engorgement which leads to nasal congestion, while asthma is expressed by a combination of smooth muscle contraction, irritability of the airways mediated by autonomic nervous reflexes, and mucus hypersecretion.

Where to now?

So far E25 has been tried out in situations where one would expect it to perform well and it has given cause for cautious optimism, but no more than that. There is now a pressing need to show whether E25 works in proper clinical trials as a treatment for asthma. A prior one might expect E25 to work better in mild allergic disease rather than the more severe cases in which the role of allergy is less certain. Unfortunately, the economics of asthma health care are such that patients with milder asthma are cheaper to treat and we already have several therapeutic options. They are an attractive market in numerical terms but intravenous administration of expensive bioengineered products is more likely to be justified economically and clinically in patients with severe disease or disease that is resistant to current heavy duty therapy.

In my judgement the real value of E25 lies in delineating the role of $\operatorname{IgE}$ in the different types and grades of asthma and in showing us whether we should be more concerned about IgE mediated hypersensitivity as a trigger for asthma or as a factor in the maintenance of chronic disease. For those of us who treat par ith whether we should be putting more effort into allergen avoidance, the most accessible part of the "trigger" side of asthma, or concentrating more on the downstream consequences which many investigators now believe may, in fact, be independent of the initiating factors (fig. 2).

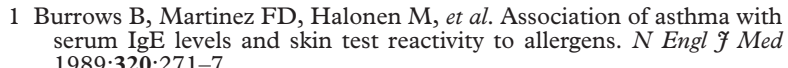
2 Ninan TK, Russell G. Respiratory symptoms and atopy in Aberdeen 304:873-5.

Martinez FD, Wright AL, Taussig LM et al. Asthma and wheezing 4 Bentley AM, Menz G, Storz C, et al Identification of T lym

macrophages and activated eosinophils in the bronchial mucosa in intrinsic asthma. Relationship to symptoms and bronchial re-
5 Johnston SL, Pattemore PK, Sanderson G, et al. Community study of Jhnston SL, Pattemore PK, Sanderson G, et al. Community study of
the role of virus infections in exacerbations of asthma in school
children in the community. $B M \exists 1995 ; 310: 1225-9$.

6 Corne JM, Smith S, Schreiber J, et al. The role of rhinovirus in 155:A63.

7 Wallis DN, Webb J, Brooke D, et al. A major outbreak of asthma associated with a thunderstorm. BMP $1996 ; 312: 601-4$.
Ehnert B, Lau-Schadendorf S, Weber A, et al. Reducing domestic exposure to dust mite allergen reduces bronchial hyperreactivity in
sensitive children with asthma. F Allergy Clin Immunol 1992;90:135-8. Platts-Mills TAE, Tovey ER, Mitchell EB, et al. Reduction of bronchial hypers.

10 Chan-Yeung M, Lam S, Koener S. Clinical features and natural history of occupational asthma due to western red cedar (Thuja plicata). Am Chan-Yeung M, Leriche J, Maclean L, et al. Comparison of cellular and protein changes in bronchial lavage fluid of symptomatic and
asymptomatic patients with red cedar asthma on follow-up exasymptomatic patients with red cedar
amination. Clin Allergy 1988;18:359-65. 12 Purkerson. J, Isakson P. A two signal model for regulation of immunoglobulin isotype switching. FASEB f 1992;6:3245-52.
13 Punnonen J, Aversa G, Cocks BG, et al. Role of IL-4 and IL-13 in synthesis of IgE and expression of CD23 by human B-cells. Allergy Bradding P, Feather I, Howarth PH, et al. Interleukin-4 is localised to and released by human mast cells. $\mathcal{F}$ Exp Med 1992;176:1381-6. of eosinophil differentiation factor (interleukin-5) and its effect on human and mouse B cells. Immunol Rev 1988;102:29-50.

16 Lopez $\mathrm{AF}$, Sanderson CJ, Gamble $\mathrm{KR}$, et al. Recombinant human Exp Med 1988;167:219-24.

17 Bradding P, Roberts JA, Britten KM et al. Interleukins-4, -5, -6 and TNF-alpha in normal and asthmatic airways. Evidence for the human
mast cell as an important source of these cytokines. Am $尹$ Respir Cell
Mol Biol 1994;10:471-80.

8 Broide DH, Paine MM, Firestein GS. Eosinophils express IL-5 and GM-CSF mRNA at sites of allergic inflammation in asthmatics. $f$

19 Salvi SS, Semper AE, Tuck A, et al. Human lung epithelial cells expres IL-5 mRNA. I Allergy Clin Immunol 1998;101 (in press).

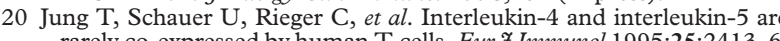

21 Humbert M, Durham SR, Ying S, et al. IL-5 and IL-5 mRNA and protein in bronchial biopsies from patients with atopic and nonatopic asthma. Evidence against "intrinsic" asthma being a distinct imCorrigan CJ, Haczku A, Gemou-Engesaeth V, et al. CD4 T-lymphocyte activation in asthma is accomplished by increased serum con-

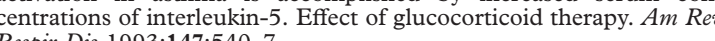
Bentley AM, Maestrelli P, Fabbri LM, et al. Activated T lymphocytes and eosinophils in the bronchial mucosa in isocyanate-induced asthma.

24 Frew AJ, Chan H, Lam S, et al. Bronchial inflammation in occupational

151:340-4.
Maestrelli P, Occari P, Turato G, et al. Expression of IL-4 and IL-5 26 Maestrelli P, Del Prete GF, de Carli M, et al. Activated CD8 T ymphocytes producing interferon-gamma and interleukin- 5 in bron27 Corrigan CJ. Elevated IL-4 secretion by T-lymphocytes: a feature of atopy or asthma? Clin Exp Allergy 1995;25:485-7.
28 Barlisi CG, Falcone A, Billah MM, et al. T-cells are the predominant 
source of IL-5 but not IL-4 mRNA expression in the lungs of antigen-
challenged mice. Am ₹ Respir Cell Mol Biol 1996:15:420-8. 29 Kips JC, Pauwels RA. Animal models of asthma. Clin Asthma Rev 1997; 1:45-53. STelts DM, Zurcher JA, et al. Involvement of IL-5 in a
30 Kung TT, Ste murine model of allergic pulmonary inflammation: prophylactic and
therapeutic effect of an anti-IL-5 antibody. Am $₹$ Respir Cell Mol Biol 1995;13:360-5.
Mauser PJ, Pitman A, Witt A, et al. Inhibitory effect of the TRFK-5 anti-IL-5 antibody in Mauser PJ, Pitman AM, Fernandez X, et al. Effects of an antibody to
IL-5 in a monkey model of asthma. Am $尹$ Respir Crit Care Med 1995; 152:467-72. Varney VA, Hamid QA, Gaga M, et al. Intur immunotherapy on cellular infiltration and cytokine mRNA expression
during allergen-induced late-phase cutaneous responses. 9 Clin Invest 1993;92:644-51.
4 Rawlins MD, Wood SM, Mann RD. Hazards with desensitizing vac-

5 Lockey RF, Benedict L, Turkeltaub PC, et al. Fatalities from immunotherapy and skin testing. F Allergy Clin Immunol 1987;79:660-7.
36 Shields R, Whether WR, Zionchek K, et al. Inhibition of allergic reactions with antibodies to IgE. Int Arch Allergy Appl Immunol 1995;107: with antibodies to IgE. Int Arch Allergy Appl Immunol 1995;107:
308-12.
Davis F, Gosser L, Pinkston K, et al. Can anti-IgE be used to treat allergy? Springer Semin Immunopathol 1993;15:51-73. 38 directed against IIE. F Immunol 1993; 151:2623 - 32.
39 Fahy JV, Fleming HE, Wong HH, et al. The effect of an anti-IgE Fahy JV, Fleming $\mathrm{HE}$, Wong $\mathrm{HH}$, et al. The effect of an anti-IgE
monoclonal antibody on the early and late-phase responses to allergen
inhalation in asthmatic subjects. Am ₹ Respir Crit Care Med 1997;155: 1828-34.
Boulet L-P, Chapman, KR, Côté J, et al. Inhibitory effects of an antiBoulet L-P, Chapman, KR, Côté J, et al. Inhibitory effects of an anti-
IgE antibody 25 on allergen-induced early asthmatic response. $A m$

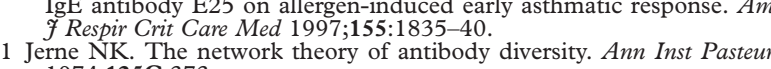
42 Bettler B, Texido G, Raggini S, et al. IgE-binding site in Fce receptor
(FceRII/CD23) identified by homolog-scanning mutagenesis. $\mathcal{F}$ Biol Chem 192;267:185-91.
Casale TB, Bernstein IL, Busse WW, et al. Use of an anti-IgE humanized monoclonal antibody in ragweed-induced allergic rhinitis. F Allergy
molition Clin Immunol 1997; 100:110-21.
Cockcroft DW, Ruffin RE, Frith PA, al. Determinants of allergenCockcroft DW, Ruffin RE, Frith PA, et al. Determinants of allergen-
induced asthma: dose of allergen, circulating IgE antibody con-
centration and bronchial responsiveness to inhaled histamine. Am Rev
Respir Dis 1979;120:1053-8. 